\title{
Russians in Treatment: The Evidence Base Supporting Cultural Adaptations
}

\author{
Tomas Jurcik ${ }^{1}$, Yulia E. Chentsova-Dutton ${ }^{2}$, Ielyzaveta Solopieieva-Jurcikova ${ }^{1}$, and Andrew G. Ryder ${ }^{1,3}$ \\ ${ }^{1}$ Concordia University, Montreal, Canada \\ ${ }^{2}$ Georgetown University, Washington, DC \\ ${ }^{3}$ Jewish General Hospital, Montreal, Canada
}

\begin{abstract}
Objective: Despite large waves of westward migration, little is known about how to adapt services to assist Russian-speaking immigrants. In an attempt to bridge the scientist-practitioner gap, the current review synthesizes diverse literatures regarding what is known about immigrants from the Former Soviet Union. Method: Relevant empirical studies and reviews from cross-cultural and cultural psychology, sociology, psychiatric epidemiology, mental health, management, linguistics, history, and anthropology literature were synthesized into three broad topics: culture of origin issues, common psychosocial challenges, and clinical recommendations. Results: Russian speakers probably differ in their form of collectivism, gender relations, emotion norms, social support, and parenting styles from what many clinicians are familiar with and exhibit an apparent paradoxical mix of modern and traditional values. While some immigrant groups from the Former Soviet Union are adjusting well, others have shown elevated levels of depression, somatization, and alcoholism, which can inform cultural adaptations. Conclusions: Testable assessment and therapy adaptations for Russians were outlined based on integrating clinical and cultural psychology perspectives.
\end{abstract}

Keywords: Russian immigrants; treatment adaptation; acculturation; assessment; collectivism

Does not man, perhaps, love something besides well-being? Perhaps he is just as fond of suffering? Perhaps suffering is just as great a benefit to him as well-being? Fyodor Dostoyevsky (1864/2008, p.30)

Why concern ourselves with Russians and their culture? Psychologists in the English-speaking world have been inundated with information on how to adapt their treatments to various groups-so why another one and, on top of that, why the Russians? During the Cold War, one of the last things Western governments wanted was Russian influence, yet half a century later Russians are an integral part of the rich cultural mosaic of "Western" societies (Leipzig, 2006). There are numerous practical and theoretical reasons to take an interest in Russian-speaking immigrants.

The United States, Canada, Israel, Germany and other

We thank Dr. Laurence Kirmayer and two anonymous reviewers for their suggestions during the preparation of an earlier version of the manuscript.

Please address correspondence to: Tomas Jurcik or Andrew G. Ryder, Psychology Department, Concordia University, 7141 Sherbrooke St. West. Montréal, Québec H4B 1R6, Canada, E-mail: t_jurcik@live.concordia.ca or andrew.ryder@concordia.ca western countries have absorbed a large proportion of immigrants originating from the Former Soviet Union (FSU), or now the Commonwealth of Independent States (CIS), after the collapse of communism and the dissolution of the Soviet Union in 1991. The CIS is a loose association representing a large proportion of FSU countries, with members including Russia, Moldova, Belarus, and (unofficially) Ukraine, among others. The Immigration and Naturalization Service in the United States recently estimated 450,000 documented immigrants from the CIS between 1995 and 2005, notwithstanding up to hundreds of thousands of undocumented cases (Lashenykh-Mumbauer, 2005). Israel has absorbed over one million people from the FSU (see Mirsky, 2009), and, furthermore, Citizenship and Immigration Canada (2010) reports over 7,600 new permanent residents in 2009 alone from Russia, Ukraine, Belarus, Moldova, Armenia, Azerbaijan, Kazakhstan, and Georgia (which was part of the CIS). These absorption rates are notable, even staggering in some cases.

Despite the waves of westward post-communist migration, relatively little research has been conducted on Russianspeaking migrants to North America. Of particular relevance to clinical psychologists, there is a paucity of information on treatment outcomes in existing mental health services and on how current therapeutic strategies could be culturally adapted to improve these outcomes. Clinicians have argued that Russians are underrepresented in health service use, advocating 
for more research (Hundley \& Lambie, 2007; Leipzig, 2006). Given the high prevalence rates of specific symptoms related to depression, somatization and alcohol abuse found in this group (e.g., Bromet et al., 2005; discussed below), underrepresentation suggests that these problems are not adequately addressed.

The Russian cultural context also fosters a set of values that contrast with other cultural groups that are more commonly studied. For example, while many psychologists will be aware that Russian society tends to encourage values that we would call collectivistic, there are several different ways to conceptualize and negotiate interdependent relationships. Collectivistic societies are not identical, and we cannot simply generalize from East Asian collectivism. Likewise, despite being Europeans, Russian emotion norms, gender relations, and parent-child relations are considerably different from those found in the West. Russians do not fall neatly into "White" (i.e., typically Western European heritage) or "Asian" ethnoracial blocks: the construction of broad ethnoracial categories arguably negates unique histories and identities.

These and other characteristics all have assessment and therapy implications mostly overlooked by psychologists. Indeed, adapting mental health services for Russianspeaking immigrants specifically is important for clinicians working with these clients, since meta-analytic findings suggest that adapted treatments that focus on a particular cultural group, rather than on several groups, tend to be more effective (Griner \& Smith, 2006). Such efforts must commence with a consolidation of what we do know about Russian cultural contexts, a task that we begin here.

The goals of this review paper are hence threefold. The first section, on cultural considerations, will attempt to sensitize North American and Western European clinicians and researchers to Russian culture of origin issues that may influence the process of assessment and psychotherapy. This includes an examination of what we mean by Russian collectivism and how historical factors influenced trust, gender roles, parenting, and emotion norms in Russian society. While not all Russian clients identify with the cultural beliefs, values, and behaviours outlined, it is likely that they would have encountered these patterns throughout their lives. This knowledge offers therapists a frame or anchoring point from which they can relate to and empathize with their patients' experiences within a cultural context, regardless of whether the patient fully adheres, partly adheres, or even outright rejects its values.

In the second section, on psychosocial challenges, we will attempt to assist clinicians in recognizing patterns specific to Russian migrants in the context of general adaptation issues. These patterns include phenomena related to bicultural identity integration, socioeconomic barriers, intergenerational value conflicts, and mental health problems. While these issues affect all migrant groups, they do so in culturally specific ways.

Finally, in the recommendations section, the paper addresses the current scientist-practitioner gap; we explore how findings in basic and social research may be applied to clinical research and intervention and attempt to bridge this gap by providing research and practice recommendations. This review synthesizes literature from the limited quantitative and qualitative findings in cultural psychology and psychiatry, psychiatric anthropology, linguistics, sociology, epidemiology, as well as the authors' clinical experiences. Although not systematic, it aims to serve as a resource to assist practitioners, clinical researchers, and policy makers in adapting existing services.

\section{Cultural Considerations: Who Are Russians?}

This first section focuses mostly on culture of origin issues. We make a case for why it is important to distinguish Russians from broad European-origin groups in clinical research, and to enhance awareness of cultural nuances related to Russian forms of collectivism and social support, family and gender dynamics, as well as issues of trust that may affect therapy alliances.

Before embarking on culture specifics, however, we will briefly consider what we mean by "culture". Rather than using culture to mean "ethnic group", culture can be defined as consensually understood meanings and practices (Bruner, 1990). One way of integrating meanings (cognitions) and practices (behaviors) is through the idea of cultural scripts (Ryder et al., 2011). Scripts are cognitive, involving units of culturally salient knowledge that facilitate rapid and automatic access to information. They are also behavioral in that they are enacted, observed, and understood by others, thereby becoming part of the larger cultural context (DiMaggio, 1997). Several of what are commonly called "cultural factors" in this paper can be understood as cultural scripts, with evidence of both stability across Russian contexts and dynamic change over historical time.

Our view of culture is informed primarily by cultural psychology along with recent attempts to integrate that perspective with clinical psychology (Ryder et al., 2011). Of importance to clinicians, the adoption of a cultural psychology perspective can facilitate a shift from an emphasis on group differences to understanding how culture shapes individual psychological variation (Heine \& Norenzayan, 2006; Markus \& Kitayama, 1991). Individuals who are part of a cultural group are not simply vessels for group-level characteristics, but rather share a certain understanding as to what is expected, permitted, tolerated, or proscribed within a unique context (Chiu et al., 2010). While we retain group labels for practical purposes, these are dynamic rather than fixed categories. 


\section{Historical Factors}

Since the 1970s there has been a tendency for cultural psychology researchers to focus on Western-East Asian differences, for example, on the somatization phenomenon in China (e.g., Kleinman, 1986; Ryder et al., 2008) and on the effects of East Asian interdependence/collectivism compared with the independent/individualistic cultural contexts found in North America (e.g., Kitayama \& Cohen, 2007; Markus \& Kitayama, 1991). Migrants from Eastern Europe, on the other hand, have been all but neglected in research until recently, except for brief attention during the Cold War (e.g., Inkeles, 1950).

This neglect may have been unintentionally exacerbated by the fact that Russian-speaking immigrants are an exceptionally diverse group. They are traditionally presumed to be of European origin, but some of them are visible minorities (e.g., Tatars). Given that the Russian empire of the 17th to 20th century spanned across a massive land mass in Eurasia, those who view themselves as having been influenced by Russian culture vary in nationality, first language spoken, and political and religious affiliation, which all have specific historical ramifications. For example, the Ukrainians endured a manufactured famine under the time of Stalin, which led to millions of deaths and continues to play a role in tense Russian-Ukrainian relations (McCarthy, 2009). The Jews faced discrimination and pogroms in the 19th and early 20th centuries, and although they were later considered to be full citizens under communism whose party line (at least officially) deplored anti-Semitism, quotas for Jews continued in various professions (Levin, 1990). Furthermore, practicing religious groups, including the Russian Orthodox Christian majority, were heavily oppressed during most of the 20th century.

Given this complexity, readers might be wondering, who are Russians exactly? Despite the heterogeneity, migrants from the FSU typically share a common language (i.e., Russian), education system, traditions, values, history under communism, and experience of sudden transition to capitalism. Many of these migrants identify themselves ethnically, culturally, and/or linguistically as Russian (or have hybrid identities, such as Russian-Ukrainian), and thus generally have been exposed to and/or have adopted Russian values and norms described below. We will generally use the term "Russian-speaking" to be inclusive of such a heterogenous group.

\section{Russian Collectivism}

Cross-cultural survey data indicating high Russian levels of collectivism (Oyserman et al., 2002) are not surprising, given that an emphasis on collectivism versus individualism is common to most non-"Western" cultural groups. It is pernicious to assume, however, that all forms of collectivism re- semble what is observed in East Asian societies, where much cultural research has been carried out. As will become apparent, Russian collectivism is considerably different from the much more frequently discussed collectivisms of East Asia.

Russian collectivism was probably fostered over centuries due to severe climate, geophysical challenges (e.g., dense forests, bogs, mountains), hostile incursions from Mongols, Tatars, and other groups and a history of serfdom. Survival thus required interdependence or Sobornost, a type of communal spirit (e.g., between agrarian workers) and the "need to look both ways" in the harsh environment (Vlachoutsicos, 2001, p.154). The communist regime that lasted through much of the 20th century involved forced collectivism, including collective farming (kolkhozy) and centralization of political and economic power. On the other hand, there had been rival ideas pointing to political and economic reforms that started in the 18th century that culminated in glasnost and perestroika during communism in the $1980 \mathrm{~s}$, leading to the more individual focus observed today (Naumov \& Puffer, 2000).

Historical experience with totalitarianism, bureaucratic failure, recent economic instability, and a widening socioeconomic spectrum in postcommunist years may have maintained a trend of caution, making mutual and reciprocal reliance on family and friends paramount (see Goodwin, 2008; Shlapentokh, 2004). Thus, reciprocal unsolicited advice giving (along the lines of "I know how I can help you or who can help you") may be especially adaptive in socially, politically, and physically threatening or uncertain environments. Most notably, studies have suggested that Russians (in Russia) tend to receive more imposed social support such as unsolicited encouragement, information, and care (Chentsova Dutton, 2012) and tend to give more unsolicited advice related to health and practical matters (Chentsova-Dutton \& Vaughn, 2011) compared with European Americans. Russian participants do not view unsolicited support from family as intrusive. Thus, pragmatic "in your face" social support is a distinct aspect of Russian collectivism that downplays interpersonal harmony and autonomy (see also Chirkov \& Ryan, 2001) and may be viewed as a sign of caring and communal bonding.

Violations of autonomy (as perceived in Western cultures that focus on independence) or loss of face in being the recipient of unsolicited advice (in East Asian interdependent cultures valuing harmony) may not be as pertinent to Russians compared with practical obligations (Chentsova-Dutton \& Vaughn, 2011). For example, Russian immigrants described "a very supportive person" as one who "shows real (not in words only, but also in actions) support at any time of the day or night", "knows how to suggest specific actions and immediately start bringing them to life," and "will guess" when a loved one "needs to talk or spend time with him." (Chentsova-Dutton \& Santos, 2012). Russian collectivism 
has thus shaped cultural scripts for the provision of social support.

Another paradoxical aspect of Russian collectivism is a phenomenon referred to as blat, a use of informal connections and bribery to obtain goods and services bypassing formal procedures (Ledeneva, 2008). When encountering problems with public institutions, Russians and Ukrainians are more likely to make use of such "anti-modern" tactics compared with Czechs or Koreans (Rose, 1998). Compared with guanxi, a similar practice common in China, blat focuses more on one's personal benefits and thus is based on individualistic as opposed to collectivistic ethics (Ledeneva, 2008). Thus, Russian collectivism is also infused with an element of self-serving individualism (Ledeneva, 2008), with Russians showing higher levels of individualism than East Asians (see Naumov \& Puffer, 2000). In sum, Russian collectivism is unique due to its emphasis of pragmatically based unsolicited support and its extensive utilization of anti-modern informal networks for more individualistic gains.

\section{Emotions and Well-Being}

In North American cultural contexts, being influential is valued, and being motivated by high activation positive emotions (e.g., excitement) can be useful for this purpose (Tsai et al., 2006). However, other cultural groups are motivated by different ideal emotions, or emotion norms. For example, in East Asia, ideal emotions are 778 Journal of Clinical Psychology, July 2013 less focused on high arousal, such as contentment rather than excitement, perhaps because of a collectivist focus on maintaining group harmony (Tsai et al., 2006). For similar reasons strong displays of negative emotion are likely to also be discouraged (see Markus \& Kitayama, 1991).

Now consider the words of a Russian study participant responding to an open-ended question about what kind of emotions she wants her children to feel: "I would like my children to live rich emotional lives, to love and to hate, to respect and to feel contempt and fear. Someone may say that this is bad, may I daresay that we only have one life to live. We need to feel it fully, and not be like some soulless automatons" (translated from Russian; Chentsova-Dutton, 2011). Linguistic analysis has suggested that Slavic groups (Russians, Ukrainians, Poles) have cultural scripts for emotions in which genuine emotional expression is valued (whether positive or negative), with less restrained expression of negative emotions, in strong contrast to "Anglo" groups (Wierzbicka, 1992, 1999) or even East Asian ones (Markus \& Kitayama, 1991).

The very term "negative" emotions may be less accurate for this cultural context, given that it places value on experiencing and expressing them (Ries, 1997). These displays of emotion are further moderated by contextual factors. Thus self-report findings suggest that Russians exercise less control over their negative emotional expression with strangers, but more control with people they know, compared with American, Japanese, and Korean groups (Matsumoto et al., 1998). Again, this highlights how different groups traditionally posited to be collectivist demonstrate different behaviours depending on context.

Linguistic scripts may not be tightly coupled with experience, however. Whereas linguistic findings imply that Russians are familiar with a large range of emotions, other evidence suggests that Russians experience elevated rates of negative emotions as well as fewer positive ones. This is not to assume that positive emotions are absent, but rather they may be expressed in more select contexts. Thus, Russians and Ukrainians living in the United States report less joy and more anger, guilt, and sadness compared with American comparison samples (Consedine \& Magai, 2002). Compared with Euro-Americans, Russians were shown to be more motivated by sadness or negative emotions than by positive ones while expecting to complete a variety of cognitive tasks, supporting the perceived value of such emotions in a Russian context (Chentsova-Dutton, 2011).

Notably, elevated reports of sadness are corroborated in multination studies, where Russians generally report being less happy than respondents from Western countries (Veenhoven, 2001). In life-satisfaction survey data, out of 68 countries between 1999 and 2002, four European CIS countries (i.e., Russia, Ukraine, Belarus, and Moldova) were among the lowest six (Tov \& Diener, 2007); length of time under communist rule has uniquely been able to predict lower life satisfaction (e.g., Inglehart \& Klingemann, 2000). In contrast, Canada and the United States ranked 11th and 13th highest, respectively. Scoring low on life-satisfaction compared with European, American, and Asian countries has also been associated with lower mood and life expectancy and higher suicide rates in Russians (Veenhoven, 2001).

Turning to mental health, corroborating epidemiological findings from Ukraine suggest that 12-month prevalence rates of depression in women (11.3\% vs. 5\%) and 12-month (11.5\% vs. $1.7 \%)$ and lifetime (26.5\% vs. $9.3 \%)$ prevalence rates of alcoholism in men are substantially higher than those in Western Europe (Bromet et al., 2005). Exceptionally high rates of alcohol dependence in men $(69.3 \%)$ have also been found in rural Russia (Pakriev et al., 1998). Recent Russian immigrants to Israel have also reported high rates of somatization $(21.9 \%$ ), often related to heart or chest pain (Ritsner et al., 2000). Thus, lower life satisfaction closely mirrors the elevated rates of certain psychopathology and distress. In short, relative to Western Europeans and North Americans, Russians may experience more negative and fewer positive emotions, with evidence of increased rates of alcoholism and depression against a backdrop of lower life satisfaction. Overall, these findings suggest an individual's emotional life reflects a complex interaction between cultural norms about 
what emotions are acceptable or functional, culturally condoned coping styles, negative sociopolitical stressors, and individual cognitive biases.

\section{Paradoxes in Gender Relations and Parenting}

Russian society has been described as both patriarchal (Hundley \& Lambie, 2007) and matriarchal (Leipzig, 2006). Indeed, some major decision-making powers rest with men (e.g., proposal to marry), who are also expected to provide for the family financially and show gallantry towards women. Women take command of the household, children, and finances, and do so while maintaining meaningful careers (Leipzig, 2006). There is also a proliferation of multigeneration single-mother families with extended family support, especially from grandmothers, or Babushki (Utrata, 2008). Women thus play a remarkable role in maintaining family and society.

Despite their central role, domestic violence against women in Russia may be four to five times as high relative to Western countries (Horne, 1999). Significant unemployment and higher levels of alcohol disorders in men (Bromet et al., 2005) may fuel these problems. Moreover, Russian culture may foster seemingly contradictory and highly contextspecific norms regarding openness and caution in relationships ${ }^{1}$ Wierzbicka (1997) posited that relationships between family members or spouses are associated with fewer signs of openness and closeness than between friends (especially between men), with some clinical case study evidence suggesting that partners may limit personal disclosures to each other out of a fear of appearing "weak" (Hundley \& Lambie, 2007). Regardless, studies have also found Russians to be generally satisfied in their marital relationships (e.g., Saris \& Andreenkova, 2001).

While economic and sociopolitical changes may account for the decreases in life satisfaction as a whole, more detailed quantitative and qualitative research is needed to resolve some of these contrasting findings related to marriage and relationships. In any case, clinicians helping Russian families need to be aware of the mix of feminist or patriarchal attitudes and cultural scripts regarding openness in different types of relationships.

As for parenting style, it has been argued that Russian parents promote interdependent relationships in their children and foster mutual obligations (e.g., Chentsova-Dutton, 2012) as opposed to an individualistic self ${ }^{2}$ Therapists have maintained that Russian parents often have ambivalent feelings about promoting independence in their children (Leipzig, 2006). On the one hand, they expect their children to be submissive to parental authority figures, often providing them with unsolicited support (Chentsova-Dutton \& Vaughn, 2011), but on the other, there is a tendency to encourage independence or self-sufficiency (Samostoyatelnost) in the younger generation (Leipzig, 2006). Russian adolescents are similar to Americans, in that they also benefit from greater autonomy support (Chirkov \& Ryan, 2001); however, the former view their parents and teachers as more controlling (Mahovskaya, 2010). Young Russians report lower satisfaction in their relationships with family and friends, explained by lower levels of nondirective-less controlling or imposing-support (Chentsova Dutton, 2012). The double messages of obedience and independence may be confusing for youth who often live with their parents into their 20 s and beyond (Leipzig, 2006).

But what are the origins of this parental control? Some Russian social scientists maintain that generations of rule under communism led to increasing cynicism and mistrust, a sense of being controlled by the state, which may have been displaced onto parenting with children (Shlapentokh, 2006). Some children are thus subject to punitive and authoritarian parenting where parents expect "loyalty, obedience, group-mindedness, and conformity" (Ispa, 1995, p. 362; cf. Chirkov \& Ryan, 2001). These patterns may be changing with exposure through books and literature to other styles of parenting in Western societies (Shlapentokh, 2006).

Notwithstanding these critiques, some of which may be Euro-American centric and inadvertently stereotype parenting styles, Russian parents and extended family members often exhibit a high level of involvement in their children's lives, and promote academic and avocational excellence. This is mirrored by low rates of illiteracy and high numbers of internationally renowned scientists, writers, and sports people (e.g., Vygotsky, Bulgakov, and Kasparov, among many others). Thus, Russian gender relations and parenting aremarked by seeming contradictions between fostering feminism versus patriarchy and independence versus control. These contrasting values could play a role when individuals and families seek treatment in some circumstances, while in many others these dialectics can peacefully coexist.

\section{Postcommunism and Issues of Authority and Trust}

Besides gender role dynamics, issues of trust are frequently in play during clinical work with Russians (Hulewat, 1981). While Americans are inclined to trust others, especially those who share group affiliations in depersonalized categories, such as a common university or a country, for other cultural groups including Russians, trust may be based on closer relationships such as friends and neighbours (cf. Brewer \& Yuki, 2007). The ongoing threat of persecution by the State during the Soviet era probably did little to foster depersonalized trust in the present CIS. Communism led

${ }^{1}$ From the authors' experiences, strangers may place a premium on personal disclosure (see also Matsumoto et al., 1998).

${ }^{2}$ Russian children learn the saying, "Ya - eto poslednyaya bukva alfavita" which literally means "I is the last letter of the [Cyrillic] alphabet." In other words, a strong focus on the individualistic self is often discouraged. 
to restrictions in freedoms of expression, information, and movement. For example, leaving the USSR even for a short trip was extremely difficult, if not impossible for most, especially to a noncommunist country. Furthermore, the lack of social security, corruption, and high rates of poverty in contemporary economically developing CIS countries sometimes pushes people to resort to dishonest or even criminal ways of gaining income (Barry, 2009). This promotes mistrust and suspicion in Russians on a depersonalized level, a tendency to be cautious with unfamiliar people and institutions (Shlapentokh, 2006).

During the Soviet era, issues of trust and politics directly affected psychiatry-the only profession treating mental disorders at the time. Western works such as those of Sigmund Freud were restricted because of their individualistic tone, seen as going against party doctrine (Hundley \& Lambie, 2007). Pavlovian psychology was hijacked by a Marxist perspective, and psychiatry in the communist context became "an instrument of power and control" (Hundley \& Lambie, 2007, p. 245). Social deviancy led to suspicion so that political dissidents were given psychiatric diagnoses and forcibly "treated" in psychiatric facilities (Brodsky, 1988). Although psychiatry has been reformed, the power-distance between doctors and patients did not completely end with the totalitarian regime: Some physicians in Russia continue to maintain a pronounced hierarchical and authoritarian relationship with their patients (Raikhel, 2010).

Given this history, Russians may have difficulties trusting mental health and social service professionals (Leipzig, 2006). This may be further aggravated by perceived stigma of mental illness, with preference given to (non-psychiatric) medical clinics (Hundley \& Lambie, 2007). This conjecture is consistent with the higher dropout rates inminority clients (Sue, 1998) and the underrepresentation of immigrants in mental health services in general (Nadeau \& Measham, 2005), which likely extends to Russian speakers as well (e.g., Green, 2004).

In sum, the culture of origin considerations highlighted here serve to alert clinicians and researchers to the possibility that many Russians exhibit different collectivistic values and emotion norms to those found in East Asian cultural groups. Concomitantly, their cautious approach to trust, paradoxical gender roles, and experiences in family relationships are distinct from many other "White" patients that clinicians see in the consulting room. Assessment or treatment adaptations will need to take such considerations into account.

\section{Psychosocial Challenges Encountered by Immigrants: What Happens to Russians?}

The next section explores how the culture of origin considerations reviewed above may interact with the acculturation process in immigrants to a Western (especially North American) context. These include receiving country consid- erations, socioeconomic and language issues, bicultural acculturation, and common mental health problems in Russianspeaking immigrants.

\section{Receiving Country Considerations}

Demographic factors and policies towards immigrants in the receiving country play a role in influencing the adjustment process. Israel and Germany offer a striking contrast to what occurs in North America. For example, Russian Jewish migrants to Israel may arrive in family groups and receive state sponsored financial and religious support settling in their new country. In Israel, Russians comprise more than 14\% of the population (cited in Mirsky, 2009), while in other Western countries the proportion is considerably lower. FSU Jewish migrants to Germany, which has undergone extensive reforms since the Nazi era, have received considerable structural support in that country (see also Ben-Rafael et al., 2006). Russians migrants to the United States, who in recent years have tended to be non-Jewish, generally lack this level of linguistic concentration and support (LashenykhMumbauer, 2005). While most migrants from the FSU prior and up to the 1970s were Russian Jews seeking religious freedom in the United States and Israel, this pattern shifted in the 1990s after the fall of communism where most immigrants tended to be atheist or Christian and have migrated for economic reasons (e.g., Hoffmann et al., 2006; LashenykhMumbauer, 2005). Unfortunately, only sparse research exists on non-Jewish Russian-speaking immigrants to North America.

Value differences between receiving and sending countries or cultural groups could also potentially be associated with immigrant adjustment. Schwartz (2004) surveyed seven cultural orientations across various countries and generated a value map: it suggests that Russia and Ukraine might be culturally closer to Israel and the United States (emphasis on mastery), than to Germany (emphasis on egalitarianism). In need for further investigation, the types of acculturation challenges immigrants face may vary considerably depending on sending and receiving country differences, and acculturation stress may on average be perceived to be greater in some contexts than in others. Cultural variability, historical relations, and tensions between sending and receiving cultural groups as well as structural and objective social support could differentially affect the adaptation processes of new immigrants. Considerably more cross-cultural research is needed to clarify how the background of recent FSU immigrants (e.g., national allegiance, religious beliefs, values) interacts with common cultural realities within the United States, Germany, Canada, as well as Israel (see Ben-Rafael et al., 2006). 


\section{Socioeconomic, Education, and Language-Related Issues}

Russian-speaking immigrants tend to be highly educated. In one large community sample in the United States, $83 \%$ of mothers and $91 \%$ of fathers of school-aged immigrant FSU adolescents had college degrees or higher (Jones \& Trickett, 2005). This is in stark contrast to U.S. census bureau data that reported only $26 \%$ of recent immigrants in the workforce overall had obtained higher education degrees (see Camarota, 2007). However, educated migrants often do not have their qualifications recognized, ormay not speak the primary language of the receiving society well enough to obtain employment in line with qualification levels. Combined with high expectations when migrating, menial levels of work in the receiving country may increase the likelihood of selfesteem problems, depression (Leipzig, 2006), and family conflict (Hundley \& Lambie, 2007). Economic, cultural and linguistic stressors have the potential to interfere with adaptation, although many of the strengths that Russian migrants possess could well be protective and require research attention. Examples include premigration exposure to higher education, Western concepts, and European languages.

\section{Renewing Family and Social Networks}

As previously discussed, social support is a central part of Russian culture and its presence or absence continues to play an important role in the life of Russian émigrés. For example, a longitudinal study of Russian participants who migrated to Israel showed that those reporting less distress adjusting to their new life also had greater social support from family and friends (Ritsner et al., 1997). A recent review of the Israeli literature has consistently found that reduced perceived, objective, social, and family support (e.g., lack of spouse) is associated with higher psychological distress levels (Mirsky, 2009). The social buffering effect may extend itself to other important sources including religious organizations such as churches or synagogues (Hundley \& Lambie, 2007).

Establishing new or enhancing existing sources of social support is critical for the adjustment of most immigrants. Given the emphasis placed on informal support networks, however (Rose, 1998), a lack thereof may leave Russians especially vulnerable. The tendency to solve problems through informal means, even in situations when alternative routes are available (e.g., looking for a networking opportunity when there is an open job vacancy), may handicap recent immigrants when objectively such informal support is unnecessary. Research needs to be conducted on Russian economic immigrants with an emphasis on how they adapt to modern and relatively functional bureaucracies in the West, in the absence of extensive personal networks.

\section{Bicultural Acculturation in Russians}

Acculturation to a new society, marked by the adoption of new values, behaviours, and beliefs, has traditionally been viewed to be an important stressor (Berry, 2006). Bicultural identities are common in immigrants who are learning the language and culture of the adopted society while simultaneously maintaining heritage culture ties (e.g., Ryder et al., 2000). Moreover, Russian-speaking immigrants often have more than two identities; for example, besides maintaining American and Russian culture, some may also view themselves as Belarusian, Ukrainian, or Jewish (Birman et al., 2010). For the sake of simplicity the focus will be on two cultural identities, but there is room for future research exploring the effects of managing multiple identities.

But can a bicultural (or multicultural) identity have subtle and clinically relevant effects in day-to-day interaction? Bicultural individuals may switch between two different cultural frames (Benet-Martınez et al., 2002), which occurs when one culture is primed over another as in switching between languages. Marian and Kaushanskaya (2004) conducted an experiment where bilingual Russian-English speaking immigrants to the United States were asked to describe autobiographical memories in either one language or the other. Consistent with expectations, it was found that participants who were asked to describe their memories in English used more statements with personal pronouns ("I"), while those describing their memories in Russian used more group pronouns ("we"). It appears that more individualistic thinking was primed when speaking in English, whereas more collectivistic thinking was primed when speaking in Russian. Culture switching phenomena could also arise when bilingual people are in a neighbourhood, clinic, or other setting that primes one culture over another. For instance, the second author interviewed bilingual youth in a pediatric clinic for international adoptees and obtained substantially different accounts of presenting problems depending on the language used.

Shedding light on culture switching, linguistic analysis has also shown that in Russian there is a tendency to link emotions to the body more so than in English (Wierzbicka, 1999) and studies comparing monolingual English and Russian speakers describing a silent film confirm this pattern (e.g., from a Russian speaker: "judging by her face it is clear [that it is a love letter]"; Pavlenko, 2002, p. 230). When speaking about emotions, Russians also tend to have an active orientation (using verbs) compared with English speakers, who use adjectives. Describing the same film, Russian speakers used 34 verbs and 29 adjectives compared with 14 verbs and 33 adjectives used by English participants (Pavlenko, 2002). Although speculative, this linguistic link to the body may help us better understand the experience of somatization in some Russian immigrants (see Ritsner et al., 2000). More research needs to be conducted on how 
language switching phenomena may influence symptom appraisal and problem solving.

While having a bicultural identity may be beneficial, acculturation differences between family members may lead to stress or conflict. According to some researchers, children expect more autonomy and independence in accordance with Western values, which can conflict with more traditional parental values of greater authority, interdependence, and control (Mahovskaya, 2010). Children often also act as culture brokers for their less acculturated parents, thus effectively "mediating the new culture" for their family members (Jones \& Trickett, 2005, p. 405). Jones and Trickett found that $89 \%$ of FSU migrant adolescents from 229 adolescent-mother pairs acted as culture brokers (e.g., answering the telephone, explaining the education system, translating at doctor's visits). Culture brokering was associated with increased stress for these children, including problems at home, at school, and with friends. Cause and effect are difficult to disentangle, yet culture brokering was associated with less acculturated mothers who had been in the United States for shorter periods of time, suggesting that parents and the adopted society (e.g., lack of resources for parents, health care professionals who accept children as culture brokers) may play an unwitting role in initiating these problems. Future longitudinal studies exploring how Russian-speaking immigrants across various developmental stages differentially acculturate may yield interesting findings in relation to sociocultural functioning (e.g., managing parent-teacher meetings, doctor visits).

\section{Common Mental Health Problems}

Given experiences of political trauma, manmade accidents, lower life satisfaction, and related problems in CIS countries, one might expect higher levels of emotional disorders in Russian immigrants. Indeed, a recent epidemiological study in Israel (Mirsky et al., 2008) suggested that FSU immigrants $(N=844)$ are at about 1.5 times greater risk of developing a common mental disorder (e.g., depression) compared with native-born Israelis $(N=2114)$. A review of Israeli studies corroborated higher psychological distress including alcohol-related symptoms (Mirsky, 2009). Risk factors identified for mental health problems included female gender, older age, premigration mental health problems and traumatization (e.g., exposure to the Chernobyl accident), and postmigration environment (e.g., opportunities and security risks in the receiving country), including lower social support and possibly shorter length of stay in the receiving country (Mirsky, 2009).

Somatization has been found to be elevated in Russian immigrants relative to nonimmigrants or to the general population. The rates of somatization $(21.9 \%)$ as assessed by the Russian language Brief Symptom Inventory (BSI) in a community survey $(N=966)$ of FSU immigrants to Israel are comparable to those found in primary care settings (Ritsner et al., 2000). Similarly, a German longitudinal study showed higher levels of somatic symptoms including exhaustion and headaches in Russian immigrants of "ethnic German"3 descent $(N=307)$ over 2 years compared with Germans $(N=$ 310; Kirkcaldy et al., 2005). However, the immigrant sample was in poorer health at baseline compared with the native German sample, which may be indicative of elevated risk factor conditions in the source country.

The results found in North America stand in strong contrast to those obtained in Israel and Germany. A small sample study in Oregon surveyed Russian clinic $(N=17)$ and community participants $(N=42)$ using the Hopkins Symptom Checklist (HSCL-25; Hoffmann et al., 2006). The community sample had notably low rates of clinically significant depression and anxiety ( $2 \%$ each) as identified by the HSCL, lower than comparable U.S. community samples and Russian immigrants to Israel. The most common diagnoses for the clinic sample were depression $(47 \%)$, posttraumatic stress disorder (PTSD; 29\%), and adjustment disorder (18\%). The HSCL fared well in differentiating the clinical and community samples, showing high internal consistency. These findings are consistent with North American clinician accounts of frequent depression and PTSD diagnoses among CIS immigrant clients (Hundley \& Lambie, 2007).

While the Hoffmann et al. (2006) sample was small and may not have been representative of North American Russian immigrants (e.g., many were Pentecostal Christians), the low community rates of disorder may be indicative of the "healthy immigrant effect" noted in other studies (Flores \& Brotanek, 2005). Recent immigrants coming to North America tend to be in better health than the general population perhaps because of highly selective education and health criteria, unlike Israel and Germany that take a nonselective repatriation approach (Mirsky, 2009). Replication in North American epidemiological samples is needed with a larger number of screening measures, including those for alcohol dependence.

\section{Recommendations: Ways to Adapt Services to Russian Patients}

Based on inferences from the limited basic, social and epidemiological research and clinical anecdotal evidence, the following section outlines some tentative yet testable clinical recommendations for the assessment and treatment of Russian-speaking immigrants (summarized in Table 1). Our recommendations are not meant to suggest a rigid "cookbook" application to all Russian immigrants, however. Instead, they are meant to reflect a framework that views culture, mind, and brain as interconnected elements (Ryder et

\footnotetext{
${ }^{3}$ These are descendents of Germans who migrated to Russia in the $18^{\text {th }}$ century.
} 
Table 1

Social Research and Observations to Inform Assessment and Therapeutic Interventions in Clinical Research

Basic, applied social research and clinical observations and Intervention implications to be evaluated
findings

Russian collectivism: pragmatic unsolicited social support and informal networks in overcoming psychosocial stressors

Historical factors (e.g., communism) and issues of trust regarding mental health services

Feminist and traditional paradoxes in gender relations and parenting; the benefit of nondirective and autonomy support for youth

Acculturation and adaptation: Issues of biculturalism and bilingualism in the context of culture priming

Common mental health problems and traditional healing
- Consider balance between directive and nondirective approaches in therapy; explain nondirective approaches

- Enhance social support and help clients use modern bureaucracy

- Referral to cultural community or religious groups

- Model roles appropriate to Western contexts

- Acquire basic knowledge about Russian culture, literature, and history

- Enhance rapport building and inform clients about ethical responsibilities

- Reduce stigma through outreach

- Be open to a mix of feminist and traditional gender relations

- Assess and explore mixed parenting messages (independence vs. interdependence); foster autonomy and nondirective support for children when appropriate

- Assess for domestic violence if suspected

- Assess heritage and mainstream acculturation, language abilities, and socioeconomic situation

- Consider utilizing both Russian and English (use interpreter or bilingual therapist) to enhance "frame switching" for assessment and problem solving

- Discourage inappropriate use of children as "culture brokers"/translators and provide psychoeducation about mainstream culture

- Screen for depression and alcohol dependence

- Assess for posttraumatic stress disorder if indicated by trauma experience

- Somatic symptoms may be emphasized over psychological symptoms

- Assess traditional practitioner seeking (e.g., Babki), nonprescription medicine use, and herb-medication interactions - Consider using available Russian translations of symptom measures (e.g., HSCL, BSI)

Note . HSCL $=$ Hopkins Symptom Checklist BSI = Brief Symptom Inventory.

al., 2011), as part of a single, dynamic, "mutually constituted," "multi-level system" (Ryder \& Chentsova-Dutton, 2012, p.21), whose elements cannot simply be understood or targeted in isolation. For example, the cultural meaning attached to the use of traditional herbs takes place within a mind-soma (nervous system) context. Once one element of this system is altered through an intervention at one level (e.g., culture priming), the other levels are also affected (i.e., a different mental constellation of symptoms with neural correlates). The suggestions provided are thus intended to be viewed through this framework, although they await process and outcome therapy research.

\section{Cultural and Psychosocial Assessment}

It is not uncommon for Russian migrants to have experienced considerable sociopolitical and environmental challenges. Premigration and postmigration discrimination experiences (e.g., political, religious) or trauma (e.g., Chernobyl, domestic abuse) should thus not be overlooked (see Mirsky, 2009; Naryshkina et al., 2003). Psychosocial assessment with Russian immigrant patients should include level of acculturation (heritage and mainstream), proficiency in the languages of the mainstream and heritage cultures, education, employment, housing, and sources and quality of social support. Russian-speaking patients often expend con- 
siderable efforts at integration, and disparities between educational level and current employment can lead to demoralization (Leipzig, 2006).

In terms of symptomatology, vigilance should be maintained for common mental health problems including depression, anxiety disorders (including PTSD), and substance abuse, especially alcohol misuse. The HSCL is a psychometrically sound screening tool for anxiety and depression in Russian immigrants (Hoffmann et al., 2006). While somatization is ubiquitous within most cultural groups (see Kirmayer, 2001; Epstein et al., 1999), somatic symptoms are especially prevalent in migrants, including Russian Jewish immigrants to Israel compared with general community samples (Ritsner et al., 2000). American clinicians have also suggested that Russians presenting at clinics emphasize somatic symptoms over psychological ones (Hundley \& Lambie, 2007). Clinicians thus need to evaluate the meaning of any somatic symptoms carefully. Even when there is an organic "cause" for the symptoms, psychological and cultural factors may play a role in how the illness is understood and experienced, reinforcing the need for a culture-mind-brain framework (Ryder \& Chentsova-Dutton, 2012).

An expanded form of the Diagnostic and Statistical Manual of Mental Disorder Fourth Edition Text Revision (DSMIV-TR; American Psychiatric Association, 2000) cultural formulation has been found useful as a guide for clinicians assessing immigrants in general (Kirmayer et al., 2008), including coverage of topics such as psychosocial, migration, and cultural identity issues, as well as folk explanations of illness. For example, some Russian clients are known to use Znahari, traditional healers that may use herbs (Hundley \& Lambie, 2007) and Babki (old women) that remove sglaz (evil eye; Brown \& Rusinova, 2002). Other patients frequenting Russian stores may buy a variety of Russian-made non-prescription medicines and herbs. Clinicians should assess folk explanations of illness and be aware of herbs being used that might interact with psychotropic medication.

Finally, it is important to gauge expectations for the type of care desired. For example, does the client react better to direct advice or nonintrusive interventions, or a measured balance of both? Treatment delivery will often depend on the patient's familiarity with therapeutic interventions, which need to be presented with an adequate psychoeducational backdrop.

\section{Language Considerations}

Trained interpreters may assist clients with the expression of concerns and nuanced emotions (e.g., Paniagua, 2005). However, utilizing children or adolescents as culture brokers is to be avoided whenever possible as it risks causing undue stress (Curtis \& Trickett, 2009). Interpreters should preferably meet the clinician prior to and subsequent to the interview for briefing and debriefing purposes (Sattler, 2001).
Interpreting or language switching in therapy may have clinical implications that go beyond the direct conveyance of general information. As was mentioned, autobiographical events may be recounted differently when speaking in Russian compared with English (Marian \& Kaushanskaya, 2004). For instance, depressed patients may more likely recognize systemic contributions to their problems when speaking Russian and internal-psychological contributions when speaking English. This could affect how clients and clinicians formulate the problem (e.g., from an individual vs. systemic perspective). Switching (Benet-Martınez et al., 2002) has the potential to serve as a useful tool in generating solutions in problem-focused therapies but is in need of empirical investigation.

\section{Developing an Alliance in Therapy and Role Clarifica- tions}

Working on gaining trust is central to therapy work with many Russian immigrants (Hulewat, 1981). As described earlier, Russian-speaking patients may mistrust authority figures because of historical reasons and ongoing corruption (see Barry, 2009). Being aware of the history of communism and Soviet psychiatry can be a step in gaining trust and may require explicit acknowledgment of relevant suffering (e.g., survivors of political incarceration).Moreover, in Russia there is no licensure for psychologists and thus no recourse for unethical behaviour. Patients thus need to be made aware of how ethical codes (e.g., confidentiality) govern the behaviour of Western clinicians (Hundley \& Lambie, 2007). Such reassurance may facilitate increased trust initially, but the alliance will need to be carefully monitored throughout therapy (see Hulewat, 1981).

Other obstacles to the alliance can include patient cynicism and Russian stereotypes of North Americans (e.g., overly pragmatic, anti-intellectual, limited in their ability to connect with Russian culture). For clinicians with a large Russian client base, this could be countered by familiarizing oneself more with Russian culture (e.g., through history, politics, literature) and better understanding (rather than overpathologizing) Russian emotion scripts. While Russians probably have a less optimistic baseline than North Americans, they may be quite expressive and should not be stereotyped as morose (see Wierzbicka, 1999).

Psychoeducation on acculturation topics might include political, economic, and social systems in North America as they pertain to therapeutic work. Modeling roles within the new society potentially enhances this acculturation component. For example, therapists need to be sensitive to accepting gifts; refusals may negatively affect the alliance, however, excessive gift giving may signify the client's attempt to bargain for a more personable relationship or special treatment (see Leipzig, 2006). This may signal the need to revisit the therapeutic alliance and acknowledge client concerns. 


\section{Utilizing Social Support and Determining Directiveness}

Harnessing social support from existing networks, including family and friends (see Mirsky, 2009) and Russian community groups, can be a key aspect to therapy. To target underutilization of clinical services in the Russian-speaking community, some authors recommend outreach work in community and medical centers as well as places of worship (Hundley \& Lambie, 2007). Given the importance of informal networks (Rose, 1998), identifying key figures in such networks would allow Russian speakers to suggest services to their compatriots. Recommending established formal institutions (e.g., job banks) may be indicated in other circumstances.

Russian patients may show stoicism when dealing with suffering and thus avoid disclosure with significant others (Hundley \& Lambie, 2007). Not asking for advice directly can be considered a sign of a good relationship, and Russians compensate with unsolicited advice and support (Chentsova Dutton, 2012). Although the clinical implications are unclear, these findings support a more directive role for the clinician in certain circumstances, for example, giving specific advice about resolving an immigration problem when deemed appropriate. Tailoring therapy to find a suitable balance between directive and nondirective support (where the helper does not necessarily try to solve the problem) for a given client is probably most useful. Alternately, if a therapist decides against being directive, explaining the rationale for a nondirective approach is likely to be necessary.

\section{Family Relationships}

In terms of parent-child acculturation conflicts, the authority of the parent should not be undermined but concomitant psychoeducation may assist some parents in understanding how fostering autonomy, care, and affection, without the double messages of independence and control (see Leipzig, 2006), may reduce conflict and improve parent-child bonds. Parents should be directed to resources other than their children when seeking information about their new society (see Curtis \& Trickett, 2009).

Couple sessions may be indicated when thwarted expectations related to migration are interfering in the relationship. With the patient's consent, involving the partner in individual therapy has led to the resolution of ongoing individual and systemic problems according to some case reports. For example, inhibited disclosure for fear of appearing "weak" to the other partner interfered in the quality of one couple relationship, and discussion thereof normalized concerns and led to a resolution (Hundley \& Lambie, 2007). In more unfortunate cases, domestic violence will need to be a target of intervention (Horne, 1999).

\section{Conclusions}

A large number of recent Russian-speaking immigrants have arrived since the early 1990s and the North American research and clinical community has yet to catch up with these waves of migration. Diversity within and between FSU countries as well as rapid social and political change necessitates particular caution around cultural generalizations. Complex and dynamic interactions between culture, mind, and brain may account for variation between individuals and across time (Ryder et al., 2011). Nonetheless, some seemingly enduring trends were noted in the paper and offer a useful anchor for clinicians.

Russian contexts foster scripts for a particular kind of collectivism that focuses on mutual obligations and directive and unsolicited social support and advice giving, but does not emphasize interpersonal harmony as with East Asian groups. Parenting is generally authority focused, but also involves directive support. Patient-physician relations are also hierarchical, and because of a history of corruption and uncertainty under communism, trust can be more difficult to obtain in professional-patient relationships. Building a trusting alliance marked by empathy and modeling is paramount, as are social support systems. Acculturation stressors such as bicultural identity integration, intergenerational conflicts, and employment challenges all play a role in the adjustment process. Some challenges may be reframed as strengths, such as the potential benefits of language switching on problem solving. Although many immigrants are adjusting well, this should not encourage a policy of neglect or complacency (Hoffmann et al., 2006). Instead, this situation is an opportunity for the development of outreach and prevention programs combating stigma, and adaptations of existing mental health treatments for community members in need.

\section{Future Research}

The practitioner reviews to date on Russian patients have been based mostly on clinical observation and experience, which is a start, but not enough. Considerably more epidemiological research is required to examine rates of mental disorder in Russian-speaking immigrants compared with their nonimmigrant peers. Indeed, there is a large gap between social science and clinical research and practice: clinical outcome and process research has yet to integrate the more basic and applied research in linguistics, management, social psychology, and sociology reviewed here. For example, clinical research with Russian bilingual immigrant patients may examine the effects of language switching in therapy on problem solving behaviour, the effects of Russian versus English language use on perception of somatic symptoms, the effects of involving friends and family members on therapy outcomes, and the frequency of unsolicited versus solicited advice giving on the therapy alliance. 
Russians may exhibit different cognitive styles, possibly manifested as less trust and more cynicism compared with English-speaking Westerners (see also Bond et al., 2006); such differences could also influence the perception of common psychotherapeutic or medical interventions. Once such variables are better understood, a focus can be on developing culturally adapted treatment packages (see Griner \& Smith, 2006). Focus groups with the community may further assist in the identification of useful adaptations.

Based on the literature reviewed, adapted psychotherapy packages to be evaluated with Russian speakers might include the following: enhancement of the therapy alliance focusing on trust and utilizing a combination of directive and nondirective support (Chentsova Dutton, 2012); enhancement of social support (family, friends, religious groups) including systemic interventions; a less formal and socially friendly therapy environment that does not overstate authority (see Leipzig, 2006); and use of trained interpreters and screening instruments validated in Russian (Hoffmann et al., 2006). Flexible adaptations to treatment protocols could be evaluated in efficacy and effectiveness studies using nonadapted treatments as controls.

We also hope that this review may inspire other clinical researchers to take a more fine-grained approach to examining adaptations for culturally diverse clients by turning to a combination of clinical and nonclinical evidence bases for inspiration where necessary. In sum, the Russians are part of the "Western" cultural mosaic, but they are probably underutilizing available services or are mostly invisible to its providers. The research and clinical community still needs to fully assess the extent of this problem and understand how treatments can be adapted to make services more accessible and effective to attract this rapidly growing cultural group.

\section{References}

American Psychiatric Association. (2000). Appendix I: Outline for cultural formulation and glossary of culture bound syndromes. in diagnostic and statistical manual of mental disorders (4th ed., text rev.). Author.

Barry, M. P. (2009). Corruption in Russia: A model exploring its economic costs. Caucasian Review of International Affairs, 3(4).

Benet-Martınez, V., Leu, J., Lee, F., \& Morris, M. W. (2002). Negotiating biculturalism: Cultural frame switching in biculturals with oppositional versus compatible cultural identities. Journal of Cross-Cultural Psychology, 33(5), 492-516.

Ben-Rafael, E., Lyubansky, M., Gluckner, O., Harris, P., Israel, Y., W, J., \& Schoeps, J. (2006). Building a diaspora: Russian Jews in Israel, Germany and the USA. Brill.
Berry, J. W. (2006). Contexts of acculturation. In D. L. Sam \& J. W. Berry (Eds.), The cambridge handbook of acculturation psychology. Cambridge.

Birman, D., Persky, I., \& Chan, W. Y. (2010). Multiple identities of Jewish immigrant adolescents from the former Soviet Union: An exploration of salience and impact of ethnic identity. International Journal of Behavioral Development, 34(3), 193-205.

Brewer, M. B., \& Yuki, M. (2007). Culture and social identity. In S. Kitayama \& D. Cohen (Eds.), The handbook of cultural psychology. (pp. 307-322). Guildford Press.

Brodsky, B. (1988). Mental health attitudes and practices of Soviet Jewish immigrants. Health $\mathcal{E}$ Social Work, 13(2), 130-136.

Bromet, E. J., Gluzman, S. F., Paniotto, V. I., Webb, C. P., Tintle, N. L., Zakhozha, V., Havenaar, J. M., Gutkovich, Z., Kostyuchenko, S., \& Schwartz, J. E. (2005). Epidemiology of psychiatric and alcohol disorders in Ukraine. Social Psychiatry and Psychiatric Epidemiology, 40(9), 681-690.

Brown, J. V., \& Rusinova, N. L. (2002). “curing and crippling": Biomedical and alternative healing in postsoviet Russia. The Annals of the American Academy of Political and Social Science, 583(1), 160-172.

Bruner, J. (1990). Culture and human development: A new look. Human Development, 33(6), 344-355.

Camarota, S. (2007). Immigrants in the United States, 2007: A profile of America's foreign-born population. Backgrounder: Center for Immigration Studies. Retrieved from http://www . cis . org/articles / 2007/ back1007.pdf.

Chentsova Dutton, Y. E. (2012). Butting in vs. being a friend: Cultural differences and similarities in the evaluation of imposed social support. The Journal of Social Psychology, 152(4), 493-509.

Chentsova-Dutton, Y. E., \& Santos, H. (2012). Cultural differences in conceptions of ideal social support. (Manuscript in preparation). Georgetown University, Washington, DC.

Chentsova-Dutton, Y. E. (2011). Culture and functions of emotions. In D. Lyusin \& Y. E. Chentsova-Dutton (Chairs), Psychology of emotions. Session conducted at the Annual International Vygotsky Readings, Moscow, Russia.

Chentsova-Dutton, Y. E., \& Vaughn, A. (2011). Let me tell you what to do: Cultural differences in advice-giving. Journal of Cross Cultural Psychology. Advance online publication. doi: 10.1177/0022022111402343.

Chirkov, V. I., \& Ryan, R. M. (2001). Parent and teacher autonomy-support in Russian and US adolescents: Common effects on well-being and academic mo- 
tivation. Journal of Cross-Cultural Psychology, 32(5), 618-635.

Chiu, C.-Y., Gelfand, M. J., Yamagishi, T., Shteynberg, G., \& Wan, C. (2010). Intersubjective culture: The role of intersubjective perceptions in cross-cultural research. Perspectives on Psychological Science, 5(4), 482-493.

Citizenship and Immigration Canada. (2010). Facts and figures 2009 - Immigration overview: Permanent and temporary residents. Retrieved from http://www. cic.gc.ca/english/resources/statistics/facts2009/ permanent/10.asp.

Consedine, N. S., \& Magai, C. (2002). The uncharted waters of emotion: Ethnicity, trait emotion and emotion expression in older adults. Journal of Cross-Cultural Gerontology, 17(1), 71-100.

Dostoyevsky, F. (1864/2008). Notes from the underground. Classic House.

Epstein, R. M., Quill, T. E., \& McWhinney, I. R. (1999). Somatization reconsidered: Incorporating the patient's experience of illness. Archives of Internal Medicine, 159(3), 215-222.

Flores, G., \& Brotanek, J. (2005). The healthy immigrant effect: A greater understanding might help us improve the health of all children. Archives of pediatrics $\mathcal{E}$ adolescent medicine, 159(3), 295-297.

Goodwin, R. (2008). Social support and the wealthy porcupine: Pain, social support, money, and culture. Psychological Inquiry, 19(3-4), 179-185.

Green, T. (2004). Russian children and families. In R. Fong (Ed.), Culturally competent practice with immigrant and refugee children and families. (pp. 289308). Guildford.

Griner, D., \& Smith, T. B. (2006). Culturally adapted mental health intervention: A meta-analytic review. Psychotherapy: Theory, Research, Practice, Training, 43(4), 531.

Heine, S. J., \& Norenzayan, A. (2006). Toward a psychological science for a cultural species. Perspectives on Psychological Science, 1(3), 251-269.

Hoffmann, C., McFarland, B. H., Kinzie, J. D., Bresler, L., Rakhlin, D., Wolf, S., \& Kovas, A. E. (2006). Psychological distress among recent Russian immigrants in the United States. International Journal of Social Psychiatry, 52(1), 29-40.

Horne, S. (1999). Domestic violence in Russia. American Psychologist, 54(1), 55.

Hulewat, P. (1981). Dynamics of the Soviet Jewish family: Its impact on clinical practice for the Jewish family agency. Journal of Jewish Communal Service, 58(1), 53-60.

Hundley, G., \& Lambie, G. (2007). Russian speaking immigrants from the commonwealth of independent states in the United States: Implications for mental health counselors. Journal of Mental Health Counseling, 29(3), 242-258.

Inglehart, R., \& Klingemann, H. D. (2000). Genes, culture, and happiness. In E. Diener \& E. M. Suh (Eds.), Subjective well-being across cultures. (pp. 185218). MIT Press.

Inkeles, A. (1950). Stratification and social mobility in the Soviet Union: 1940-50. American Psychological Review, 15, 465-479.

Ispa, J. M. (1995). Ideas about infant and toddler care among Russian child care teachers, mothers, and university students. Early Childhood Research Quarterly, 10(3), 359-379.

Jones, C. J., \& Trickett, E. J. (2005). Immigrant adolescents behaving as culture brokers: A study of families from the former Soviet Union. The Journal of Social Psychology, 145(4), 405-428.

Kirkcaldy, B., Siefen, R., Wittig, U., Schüller, A., Brähler, E., \& Merbach, M. (2005). Health and emigration: Subjective evaluation of health status and physical symptoms in Russian-speaking migrants. Stress and Health: Journal of the International Society for the Investigation of Stress, 21(5), 295-309.

Kirmayer, L. J. (2001). Cultural variations in the clinical presentation of depression and anxiety: Implications for diagnosis and treatment. Journal of Clinical Psychiatry, 62, 22-30.

Kirmayer, L. J., Thombs, B. D., Jurcik, T., Jarvis, G. E., \& Guzder, J. (2008). Use of an expanded version of the DSM-IV outline for cultural formulation on a cultural consultation service. Psychiatric Services, 59(6), 683-686.

Kleinman, A. (1986). Social origins of distress and disease: Depression, neurasthenia, and pain in modern China. Yale University Press.

Lashenykh-Mumbauer, V. (2005). Difficulties of acculturation and coping strategies of recent Non-Jewish Russian immigrant women in the United States of America. Dissertation Abstracts International, 65, 11-B (UMI No. 3153761).

Ledeneva, A. (2008). "blat" and "guanxi": Informal practices in Russia and China. Comparative Studies in Society and History, 50(1), 118-144.

Leipzig, C. (2006). When Russians come to therapy. The American Journal of Family Therapy, 34(3), 219242.

Levin, N. (1990). The Jews in the Soviet Union since 1917. New York University Press.

Mahovskaya, O. I. (2010). Scenarii socializacii detey rossiyskih immigrantov vSSha. [Socialization scenarios of Russian immigrant children in the US]. Cultural-Historical Psychology, 3, 86-92. 
Marian, V., \& Kaushanskaya, M. (2004). Language-mediated self-construal and emotion in bicultural bilinguals. Journal of Memory and Language, 51, 190-201.

Markus, H. R., \& Kitayama, S. (1991). Culture and the self: Implications for cognition, emotion, and motivation. Psychological Review, 98(2), 224.

Matsumoto, D., Takeuchi, S., Andayani, S., Kouznetsova, N., \& Krupp, D. (1998). The contribution of individualism vs. collectivism to cross-national differences in display rules. Asian Journal of Social Psychology, l(2), 147-165.

McCarthy, B. (2009). 1930s famine still mars RussiaUkraine relations. Retrieved from http://www.npr. org/templates/story/story.php?storyId=106835755.

Mirsky, J. (2009). Mental health implications of migration: A review of mental health community studies on Russian-speaking immigrants in Israel. Social Psychiatry and Psychiatric Epidemiology, 44, 179-187.

Mirsky, J., Kohn, R., Levav, I., Grinshpoon, A., \& Ponizovsky, A. (2008). Psychological distress and psychiatric morbidity among immigrants from the former Soviet Union in Israel: Findings from the Israeli national health study. Journal of Clinical Psychiatry, 69, 1715-1720.

Nadeau, L., \& Measham, T. (2005). Immigrants and mental health services: Increasing collaboration with other service providers. The Canadian Child and Adolescent Psychiatry Review, 14(3), 73.

Naumov, A., \& Puffer, S. (2000). Measuring Russian culture using Hofstede's dimensions. Applied Psychology: An international Review, 49(4), 709-718.

Oyserman, D., Coon, H. M., \& Kemmelmeier, M. (2002). Rethinking individualism and collectivism: Evaluation of theoretical assumptions and meta-analyses. Psychological Bulletin, 128(1), 3.

Pakriev, S., Vasar, V., Aluoja, A., \& Shlik, J. (1998). Prevalence of ICD-10 harmful use of alcohol and alcohol dependence among the rural population in Udmurtia. Alcohol and Alcoholism, 33(3), 255-264.

Paniagua, F. A. (2005). Assessing and treating culturally diverse clients: A practical guide. (3rd ed.). Sage.

Pavlenko, A. (2002). Emotions and the body in Russian and English. Pragmatics $\mathcal{E}$ Cognition, 10(1-2), 207241.

Raikhel, E. (2010). Post-Soviet placebos: Epistemology and authority in Russian treatments for alcoholism. Culture, Medicine, and Psychiatry, 34(1), 132-168.

Ries, N. (1997). Russian talk: Culture and conversation during perestroika. Cornell University Press.

Ritsner, M., Ponizovsky, A., \& Ginath, Y. (1997). Changing patterns of distress during the adjustment of recent immigrants: A 1-year follow-up study. Acta Psychiatrica Scandinavica, 95(6), 494-499.
Ritsner, M., Ponizovsky, A., Kurs, R., \& Modai, I. (2000). Somatization in an immigrant population in Israel: A community survey of prevalence, risk factors, and help-seeking behavior. American Journal of Psychiatry, 157(3), 385-392.

Rose, R. (1998). Getting things done in an anti-modern society: Social capital networks in Russia. World Bank, Social Development Department.

Ryder, A. G., Alden, L. E., \& Paulhus, D. L. (2000). Is acculturation unidimensional or bidimensional? a headto-head comparison in the prediction of personality, self-identity, and adjustment. Journal of Personality and Social Psychology, 79(1), 49-65.

Ryder, A. G., Ban, L. M., \& Chentsova-Dutton, Y. E. (2011). Towards a cultural-clinical psychology. Social and Personality Psychology Compass, 5(12), 960-975.

Ryder, A. G., \& Chentsova-Dutton, Y. E. (2012). Depression in cultural context:"Chinese somatization," revisited. Psychiatric Clinics of North America.

Ryder, A. G., Yang, J., Zhu, X., Yao, S., Yi, J., Heine, S. J., \& Bagby, R. M. (2008). The cultural shaping of depression: Somatic symptoms in China, psychological symptoms in North America? Journal of Abnormal Psychology, 117(2), 300.

Saris, W. E., \& Andreenkova, A. (2001). Following changes in living conditions and happiness in post communist Russia: The Russet Panel. Journal of Happiness Studies, 2(2), 95-109.

Sattler, J. M. (2001). Assessment of children: Cognitive applications. Author.

Schwartz, S. H. (2004). Mapping and interpreting cultural differences around the world. In H. Vinken, J. Soeters, \& P. Ester (Eds.), Comparing cultures, dimensions of culture in a comparative perspective. Brill.

Shlapentokh, V. (2004). An autobiographical narration of the role of fear and friendship in the Soviet Union. Edwin Mellon Press.

Shlapentokh, V. (2006). Trust in public institutions in Russia: The lowest in the world. Communist and PostCommunist Studies, 39(2), 153-174.

Sue, S. (1998). In search of cultural competence in psychotherapy and counseling. American Psychologist, 53(4), 440.

Tov, W., \& Diener, E. (2007). Culture and subjective wellbeing. In S. Kitayama \& D. Cohen (Eds.), The handbook of cultural psychology (pp. 714-733). Guildford Press.

Tsai, J. L., Knutson, B., \& Fung, H. H. (2006). Cultural variation in affect valuation. Journal of Personality and Social Psychology, 90(2), 288. 
Utrata, J. M. (2008). Counting on motherhood, not men: Single mothers and social change in the new Russia. University of California, Berkeley.

Veenhoven, R. (2001). Are the Russians as unhappy as they say they are? comparability of self-reports across nations. Journal of Happiness Studies, 2(2), 111136.

Vlachoutsicos, C. C. (2001). Russian communitarianism: An invisible fist in the transformation process of russia. In D. R. Denison (Ed.), Managing organizational change in transition economies. (pp. 149206). Lawrence Erlbaum Associates.
Wierzbicka, A. (1992). Semantics, culture, and cognition: Universal human concepts in culture-specific configurations. Oxford University Press.

Wierzbicka, A. (1997). Understanding cultures through their key words: English, Russian, Polish, German, and Japanese. Oxford University Press.

Wierzbicka, A. (1999). Emotions across languages and cultures: Diversity and universals. Cambridge University Press. 